Article

\title{
Design and Experiment of a Large-Aperture Hollow Traveling Wave Ultrasonic Motor with Low Speed and High Torque
}

\author{
Jun Liu ${ }^{1}{ }^{1}$, Zi-Jie Niu ${ }^{2}$, Hua Zhu ${ }^{1, *}$ and Chun-Sheng Zhao ${ }^{1}$ \\ 1 State Key Laboratory of Mechanics and Control of Mechanical Structures, Nanjing University of Aeronautics \\ and Astronautics, Nanjing 210016, China; junl106@nuaa.edu.cn (J.L.); cszhao@nuaa.edu.cn (C.-S.Z.) \\ 2 College of Mechanical and Electronic Engineering, Northwest Agriculture and Forestry University, \\ Xi'an 712100, China; niuzijie@nwsuaf.edu.cn \\ * Correspondence: hzhu103@nuaa.edu.cn; Tel.: +86-135-0514-2058
}

Received: 17 May 2019; Accepted: 18 September 2019; Published: 23 September 2019

\begin{abstract}
To realize applications involving low speed and high torque in the high-performance actuator industry, especially in the aerospace field, we propose a novel $70 \mathrm{H}$ traveling wave rotary ultrasonic motor (TRUM) with an outer diameter of $70 \mathrm{~mm}$ and an aperture ratio of $53 \%$ (the ratio between the aperture and outer diameter). The power transmission mechanism between the stator and the rotor is analyzed, and a method for realizing low-speed-high-torque characteristics of TRUMs is proposed. ANSYS software is used to simulate the modal parameters of the stator, and the ratio $\beta$ between the normal amplitude and the tangential vibration velocity of the stator is proposed. The larger the value of $\beta$, the lower the speed and the higher the torque. Furthermore, two prototype motors are fabricated, namely, 70HA and 70HB. Compared with 70HA, the maximum no-load speed of the improved $70 \mathrm{HB}(50 \mathrm{rpm})$ is decreased by $23.1 \%$ and the maximum stall torque $(2.4 \mathrm{~N} \cdot \mathrm{m})$ is increased by $100 \%$. Besides this, with a smaller mass of $210 \mathrm{~g}$ and a higher torque density of $11.43 \mathrm{~N} \cdot \mathrm{m} / \mathrm{kg}, 70 \mathrm{HB}$ has fundamentally different mechanical characteristics.
\end{abstract}

Keywords: hollow traveling wave ultrasonic motor; low speed and high torque; finite element method; elliptical motion trajectory; mechanical characteristics

\section{Introduction}

Traveling wave rotary ultrasonic motors (TRUMs) have been widely developed worldwide. Compared with electromagnetic motors, TRUMs have drawbacks of lower efficiency and durability, but there are still some unique advantages. For instance, TRUMs can be used for direct drive with low mass and speed and high torque and power density, and they have a high holding torque when the power is off. As such, TRUMs are widely applicable as high-torque drivers, especially in short-term, non-sustainable workplaces. However, because of the limitation of their driving mechanism, TRUMs have poorer low-speed-high-torque characteristics compared with those of standing wave ultrasonic motors (SUMs). Currently, the maximum no-load speed of TRUMs of various sizes is hundreds of rotations per minute and the maximum stall torque is only around $1 \mathrm{~N} \cdot \mathrm{m}$. By contrast, for a SUM with the same outer diameter as a TRUM, the maximum no-load speed is $10-20 \%$ that of the TRUM, while the maximum stall torque is $5-10$ times that of the TRUM [1,2]. To date, two main methods have been used to reduce the speed and increase the output torque of TRUMs. Previous studies have shown that the TRUM limiting speed is inversely proportional to the square of the outer diameter and the output torque is proportional to the square of the outer diameter; therefore, the first method involves increasing the outer diameter [3-5]. The second method is to use novel structures, such as double-stator 
motors or single-stator with two-sided piezoelectric ceramics motors, to increase the input and output power and the output torque of TRUMs [6-8]. Nevertheless, those methods saddle TRUMs with disadvantages, such as large volume, complicated structure, and high power consumption, making them unsuitable for aerospace applications.

Previous studies of low-speed-high-torque TRUMs have yielded the following results: An et al. developed a $\varnothing 60 \mathrm{~mm}$ dual traveling wave rotary ultrasonic motor with a maximum speed and stall torque of $60 \mathrm{rpm}$ and $0.85 \mathrm{~N} \cdot \mathrm{m}$, respectively [9]. Glenn et al. developed a $\varnothing 80 \mathrm{~mm}$ two-sided piezoelectric rotary ultrasonic motor with a maximum speed and stall torque of $40 \mathrm{rpm}$ and $1.7 \mathrm{~N} \cdot \mathrm{m}$, respectively [10]. Kawai et al. developed a $\varnothing 70 \mathrm{~mm}$ double-piezoelectric-ceramic motor with a maximum speed and stall torque of $200 \mathrm{rpm}$ and $2.1 \mathrm{~N} \cdot \mathrm{m}$, respectively [11]. Li et al. developed a $\varnothing 60 \mathrm{~mm}$ double-piezoelectric-actuator motor with a maximum stall torque reaching $1.2 \mathrm{~N} \cdot \mathrm{m}$ [12]. Tian et al. developed a $\varnothing 90 \mathrm{~mm}$ hollow-ring motor with a maximum speed and stall torque of $106 \mathrm{rpm}$ and $1.8 \mathrm{~N} \cdot \mathrm{m}$, respectively [13]. Hu et al. developed a $\varnothing 100 \mathrm{~mm}$ large-torque pressure-equalizing motor with a maximum speed and stall torque of $58 \mathrm{rpm}$ and $2.2 \mathrm{~N} \cdot \mathrm{m}$, respectively [14]. Finally, Chen et al. developed a $\varnothing 100 \mathrm{~mm}$ novel motor using the usual piezoelectric elastic body as the rotor, and the maximum speed and stall torque were $20 \mathrm{rpm}$ and $4 \mathrm{~N} \cdot \mathrm{m}$, respectively [15].

In the present paper, we propose the 70H: a hollow TRUM with an outer diameter of $\varnothing 70 \mathrm{~mm}$ and an aperture ratio of $53 \%$ for low-speed-high-torque applications. Combined with the advantage of the motion mechanism of a standing wave longitudinal-torsional hybrid motor [16], the stator was improved by ANSYS simulation and then fabricated. Two prototype motors were assembled, referred to as $70 \mathrm{HA}$ and $70 \mathrm{HB}$, respectively. Tests of the mechanical characteristics showed that $70 \mathrm{HB}$ had lower speed and higher torque.

\section{Structure of TRUM-70H}

Figure 1 shows the structure of the $70 \mathrm{H}$ prototype motor via a three-dimensional model and a sectional view. The motor comprises a stator, a rotor, a base, and a preload nut. The stator is fixed to the base with a locknut. The rotor is located in a bearing that is assembled in the base and is in contact with the stator. The preload nut provides a preload between the stator and the rotor through the threads on the rotor. The piezoelectric ceramics (PZT- $8,0.5 \mathrm{~mm}$ thick) and the friction materials (PTFE composites, $0.25 \mathrm{~mm}$ thick) are glued to the stator and the rotor with epoxy adhesive. Compared with the mainstream solid-shaft traveling wave motor, $70 \mathrm{H}$ has a larger inner hole with the ratio of aperture to outer diameter reaching $53 \%$. Therefore, the design is more difficult because the design space of the stator and rotor is relatively smaller, the supporting web of the stator is narrower, and the amplitude of the stator may be smaller. However, $70 \mathrm{H}$ has obvious advantages too: the structure is more compact, the volume and mass are smaller, and the torque density is greater. In Figure $1, H$ is the stator thickness, $H_{1}$ is the stator tooth height, $h=\left(H+H_{1}\right) / 2$ is the distance from the stator tooth surface to the neutral plane, $H_{2}=H-H_{1}$ is the stator base thickness, $r_{h}$ is the rotor inner radius, and $r_{d}$ is the stator inner radius.

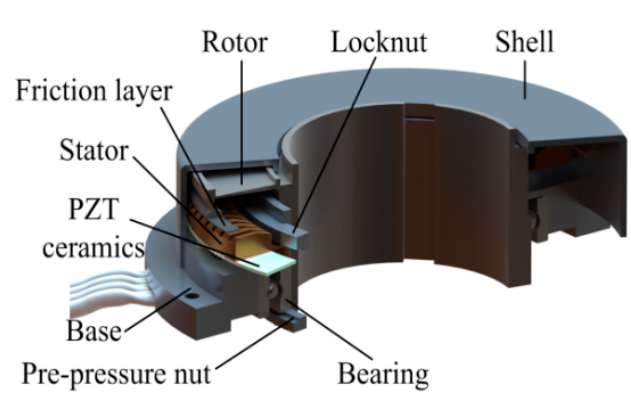

(a)

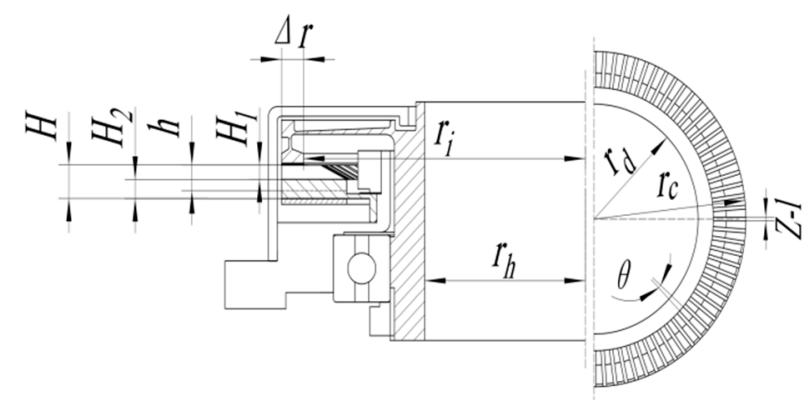

(b)

Figure 1. Hollow ultrasonic motor, $\emptyset 70 \mathrm{~mm}$ : (a) 3D structure of $70 \mathrm{H}$; (b) some essential size parameters of $70 \mathrm{H}$. 


\section{Motion and Power Transmission}

\subsection{Particle Elliptical Motion of the Stator}

The research to date on the TRUM motion mechanism is relatively mature. Applying two-phase excitation signals that differ in time phase by $\pi / 2$ to the two sets of piezoelectric ceramics polarized in a specific manner can excite $\mathrm{B}_{0 n}$ bending modes in the stator elastic body that differ in space phase by $\pi / 2$. The two orthogonal modes with the same frequency and shape are superimposed to form a traveling wave that propagates in a certain direction in the stator elastic body, thereby causing any particle on the surface of the stator to move elliptically $[17,18]$. At this time, the rotor with some friction material is in contact with the stator under a certain preload, and the elliptical motion of the stator drives the rotation of the rotor, thereby determining the motor output speed and torque (shown in Figure 2).

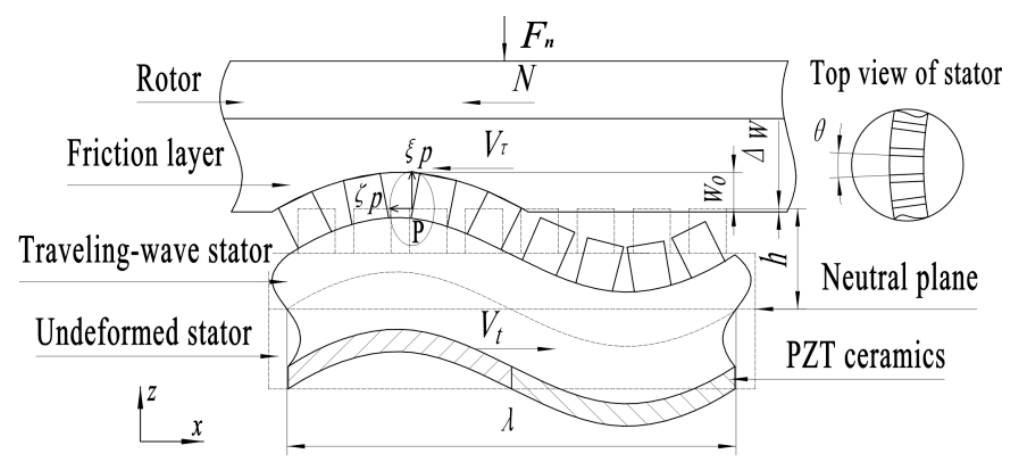

Figure 2. Contact status between stator and rotor over one wavelength.

According to the literature [19], the displacement of point $\mathrm{P}$ in the directions of $z$ and $x$ will be

$$
\left\{\begin{array}{l}
\xi_{p}=w_{0} \sin \left(k x-\omega_{n} t\right) \\
\zeta_{p}=-w_{0} h k \cos \left(k x-\omega_{n} t\right)
\end{array}\right.
$$

Then, the elliptical motion trajectory of any particle P on the stator surface can be expressed by

$$
\left(\frac{\xi_{p}}{w_{0}}\right)^{2}+\left(\frac{\zeta_{p}}{n h w_{0} / r_{c}}\right)^{2}=1
$$

where $\xi_{p}$ is the normal displacement of point $\mathrm{P}, \zeta_{p}$ is the tangential displacement, $w_{0}$ is the normal amplitude of the stator, $n$ is the working mode order, $h$ is the distance from the stator tooth surface to the neutral surface, $r_{c}$ is the outer radius of the stator, and $k=2 \pi / \lambda=n / r_{c}$.

\subsection{Limiting Speed and Stall Torque of the Motor}

According to Equation (1), the speed of point $\mathrm{P}$ in the $x$ direction can be obtained:

$$
V_{\tau}=\frac{\mathrm{d} \xi_{p}}{\mathrm{~d} t}=-w_{0} h k \omega_{n} \sin \left(k x-\omega_{n} t\right)
$$

When the stator and rotor are in contact with the traveling wave crest, the maximum tangential velocity of a stator particle can be regarded as being equal to the linear velocity of the rotor if there is no relative sliding between the stator and the rotor. Therefore, the theoretical limiting speed of the motor can be expressed as

$$
N_{\max }=V_{\tau \max }=-w_{0} h k \omega_{n}=-\frac{60 h n f_{m} w_{0}}{r_{c}{ }^{2}}
$$

where $\omega_{n}$ is the vibration angular frequency and $f_{m}$ is the modal frequency. 
When the motor is working, the rotor with friction material is pressed against the traveling wave stator under the preload. Because the friction layer is softer than the rotor material, it can be assumed that only the friction layer is subjected to contact deformation, with the rotor itself not undergoing elastic deformation. When the motor is not working, the compression of the friction layer is

$$
\Delta w=F_{n} / k_{n}
$$

where $F_{n}$ is the preload acting on the rotor and $k_{n}$ is the equivalent stiffness coefficient of the friction layer.

According to contact force analysis, the force between the stator and rotor can be decomposed into a normal contact force and a tangential friction force. In the range of elastic contact, it can be assumed that (i) the normal contact force is proportional to the compression of the friction layer and (ii) the tangential friction force obeys Coulomb's law of friction. If the average dynamic friction coefficient is $\mu_{d}$, then the theoretical limits of the normal contact force and the tangential friction force are

$$
\begin{gathered}
f_{n \max }=k_{n} g_{m}=k_{n}\left(w_{0}+\Delta w\right) \\
f_{\tau \max }=\mu_{d} f_{n \max }
\end{gathered}
$$

The limiting stall torque of the motor is

$$
M_{T \max }=\sum_{e=1}^{Z} \iint_{f_{\tau}(e)} r \mathrm{~d} f_{\tau}=\sum_{e=1}^{Z} \iint_{S(e)} \frac{r f_{\tau \max }}{S(e)} \mathrm{d} S=\sum_{e=1}^{Z} \iint \frac{f_{\tau \max }}{\pi\left(r_{c}^{2}-r_{i}^{2}\right)-Z l \Delta r} r^{2} \mathrm{~d} \theta \mathrm{d} r
$$

where $r_{i}$ is the inner radius of the friction layer, $Z$ is the number of contacted stator teeth, $l$ is the tooth spacing, $\Delta r$ is the radial width of the friction layer, and $\theta$ is the circumferential angle of a single tooth.

Equations (4) and (8) show the following. (i) Increasing the normal amplitude can increase both the stall torque and the limiting speed of the motor. (ii) Decreasing the axial distance $h$ between point $P$ and the neutral layer will reduce the tangential displacement $\zeta_{p}$ so as to achieve a lower rotation speed of the motor. (iii) The tangential speed $V_{\tau}$ is inversely proportional to the wavelength $\lambda$; therefore, decreasing the modal frequency can enlarge the wavelength and reduce the speed.

\section{Optimization of Stator Characteristic Parameters}

\subsection{Realization of Low-Speed-High-Torque Characteristics}

For all types of ultrasonic motor, the stator amplitude is an important indicator of motor performance: the larger the amplitude, the greater the mechanical energy converted from electrical energy [20]. In practice, the speed is regulated mainly by driving signal frequency and voltage, which is essentially controlled by changing the amplitude [21]. If the motor structure is constant, then the driving frequency is adjusted from high to low in the design band; if the voltage is constant, then the motor speed is adjusted from low to high. The closer the driving frequency to the modal frequency, the larger the stator amplitude and the higher the motor speed. The stall torque measured at the maximum speed point is also the largest. Similarly, if the driving frequency is constant, then within a certain range, the larger the driving voltage, the larger the stator amplitude, the motor speed, and the stall torque.

At present, low-speed-high-torque characteristics are reflected mainly in standing wave motors, especially the longitudinal-torsional hybrid motor, and are difficult to achieve in traveling wave motors because the normal and tangential vibrations of the stator elliptical motion of a hybrid motor are independent. However, the normal and tangential vibrations are coupled in a traveling wave motor; that is, the tangential displacement of a stator surface particle is induced by the normal bending vibration [22,23]. Therefore, increasing (respectively, decreasing) the normal motion component, which means the normal amplitude and can represent the maximum stall torque, will inevitably increase (respectively, decrease) the tangential motion component, which means the tangential velocity can 
represent the limiting speed. From the perspective of the mechanism of elliptical motion, when the external drives are adjusted, an increase or decrease of the amplitude can be considered as enlargement or reduction of the elliptical motion trajectory, as shown in Figure 3a.

However, for the longitudinal-torsional hybrid motor, the normal vibration and tangential vibration can be adjusted independently so that the size and shape of the elliptical motion trajectory can both change. Inspired by this, the size and shape of the elliptical motion in traveling wave motors should be changed to achieve low-speed-high-torque characteristics. Specifically, we should try to increase the normal amplitude as much as possible while reducing the tangential amplitude. That is to say, we must increase the ratio of the long axis (normal) to the short axis (tangent) of the elliptical motion trajectory. However, the stator characteristic parameters affect not only the elliptical motion directly, but also the amplitude. In other words, the amplitude is an intermediate dependent variable that affects the motor speed and output torque, whereas the characteristic parameters of the external drives and the stator are independent variables. According to the above analysis, adjusting the external drives can change only the size of the elliptical motion but not its shape. Therefore, to change the ratio of the long axis to the short axis, the stator characteristic parameters must be changed to make the elliptical motion trajectory tall and thin, as shown in Figure $3 \mathrm{~b}$.

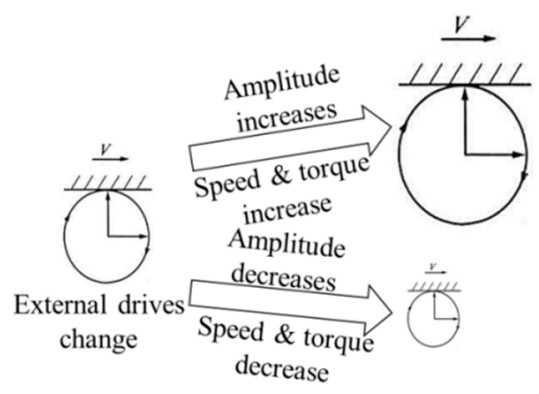

(a)

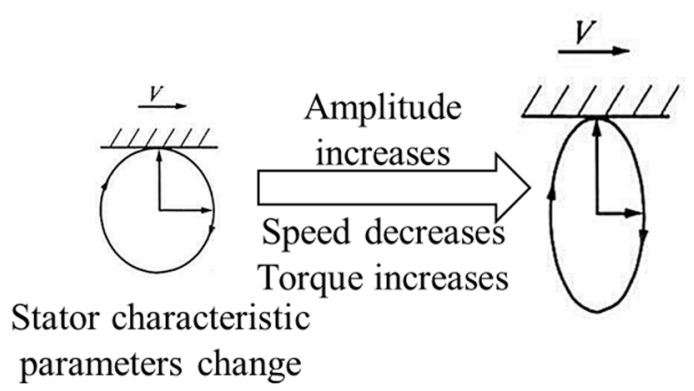

(b)

Figure 3. Comparison of the effects of changing external drives and changing the stator characteristic structure on elliptical motion: (a) change of external drives and (b) change of stator characteristic structure.

Accordingly, in the case of the same external drives and stator and rotor inner and outer diameters, to achieve low-speed-high-torque characteristics in a traveling wave motor, we should increase the stator amplitude $w_{0}$ as much as possible for higher mechanical output power but reduce $n, h, l$, and $f_{m}$. In the final analysis, we adjust the four stator characteristic parameters of (i) modal order $n$, (ii) stator base thickness $\mathrm{H}_{2}$, (iii) stator tooth height $H_{1}$, and (iv) tooth spacing $l$.

\subsection{Finite Element Modeling}

Using the modal analysis and harmonic response analysis of ANSYS 15.0 finite element software, the stator modal shape, modal frequency, normal amplitude, and tangential velocity can be obtained intuitively. Herein, we define the ratio $\beta$ between the normal amplitude and tangential vibration velocity at the same modal frequency and use it to measure the low-speed-high-torque characteristics of the motor; the larger $\beta$ is, the more remarkable those characteristics are.

The material properties of the $70 \mathrm{H}$ stator are given in Table 1 . Piezoelectric ceramic is a smart material that has elastic constants, piezoelectric constants, and permittivity constants. The damping ratio was set to $0.8 \%$ and the driving voltage was set to $100 \mathrm{~V}_{\mathrm{pp}}$ [24,25]. The working mode of the finite element method (FEM) simulation is shown in Figure 4a. The simulated vibration modal frequency of the stator was $51.2 \mathrm{kHz}$, the amplitude was $1.41 \mu \mathrm{m}$, the tangential velocity was $0.2435 \mathrm{~m} / \mathrm{s}$, and $\beta$ was 5.79 , as shown in Figure 4 b. 


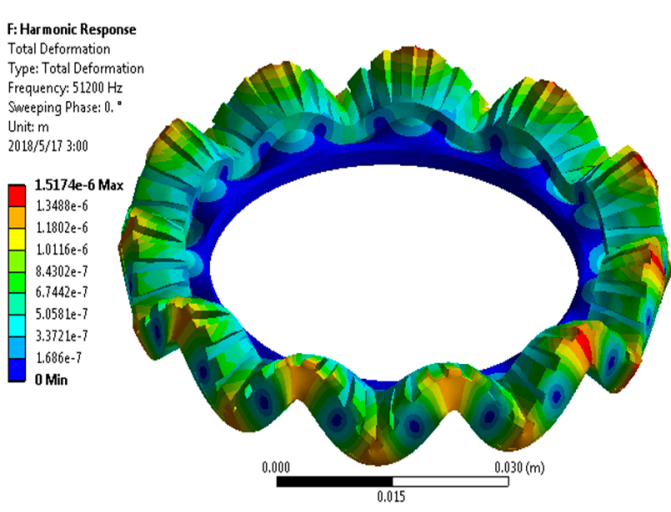

(a)

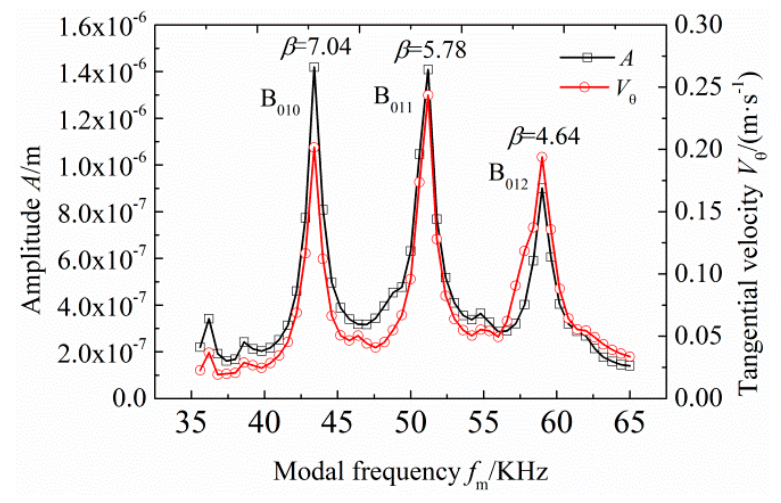

(b)

Figure 4. (a) $\mathrm{B}_{011}$ working mode of $70 \mathrm{HA}$ and (b) simulation curves of the stator vibration parameters of $70 \mathrm{HA}$.

Table 1. Properties of the stator materials.

\begin{tabular}{|c|c|c|c|c|c|c|c|}
\hline Property & QSn6.5 Phosphor Bronze & \multicolumn{6}{|c|}{ PZT-8 Piezoelectric Ceramic } \\
\hline \multirow[t]{2}{*}{ Mass density $\left(\mathrm{kg} / \mathrm{m}^{3}\right)$} & \multirow[t]{2}{*}{8800} & \multicolumn{6}{|c|}{7500} \\
\hline & & 120.6 & 53.5 & 51.5 & 0 & 0 & 0 \\
\hline \multirow{5}{*}{ Young's modulus (GPa) } & \multirow{5}{*}{110} & 53.5 & 120.6 & 51.5 & 0 & 0 & 0 \\
\hline & & 51.5 & 51.5 & 104.5 & 0 & 0 & 0 \\
\hline & & 0 & 0 & 0 & 31.3 & 0 & 0 \\
\hline & & 0 & 0 & 0 & 0 & 31.3 & 0 \\
\hline & & 0 & 0 & 0 & 0 & 0 & 34.6 \\
\hline \multirow[t]{3}{*}{ Poisson's ratio } & \multirow[t]{3}{*}{0.3} & & & . & & & \\
\hline & & & & 0 & -4 & 11 & \\
\hline & & & & 0 & -4 & & \\
\hline \multirow{4}{*}{ Piezoelectric constants $\left(\mathrm{C} / \mathrm{m}^{2}\right)$} & \multirow{4}{*}{$\cdots$} & & & 0 & 1 & & \\
\hline & & & & 0 & c & & \\
\hline & & & & 10 & 3 & & \\
\hline & & & & .3 & c & & \\
\hline \multirow{3}{*}{ Permittivity constants (F/m) } & \multirow{3}{*}{$\cdots$} & & 6.04 & 0 & 0 & \multirow{3}{*}{$\times 10^{-9}$} & \\
\hline & & & 0 & 6.04 & 0 & & \\
\hline & & & 0 & 0 & 6.04 & & \\
\hline
\end{tabular}

\subsubsection{Influence of the Vibration Mode on the Motor}

The working mode of a traveling wave motor is represented by $\mathrm{B}_{0 n}$, where $n$ is the number of traveling wave wavelengths as well as the modal order. To better generate a traveling wave, the sum of the bending waves of the piezoelectric ceramic is designed to be the same as the expected mode. Therefore, an odd-order working mode is generally selected for the stator. Furthermore, the piezoelectric ceramic should be adjusted accordingly when the working mode changes, as shown in Figure 5. The influence of $n$ on the stator vibration parameters can be simulated by finite element analysis, as shown in Figure 6. There are clearly many design choices for the motor working mode. The smaller the value of $n$, the lower the working mode order, the lower the stator modal frequency, the larger the amplitude, the smaller the tangential speed, and the larger the value of $\beta$. However, if the working mode order is too low, the modal frequency may be lower than the lower limit of the ultrasonic frequency $(20 \mathrm{kHz})$. Therefore, the $\mathrm{B}_{09}$ working mode was adopted for lower speed and higher torque. 


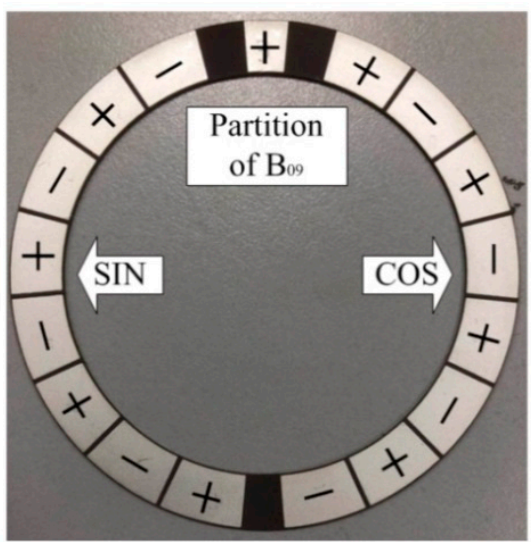

(a)

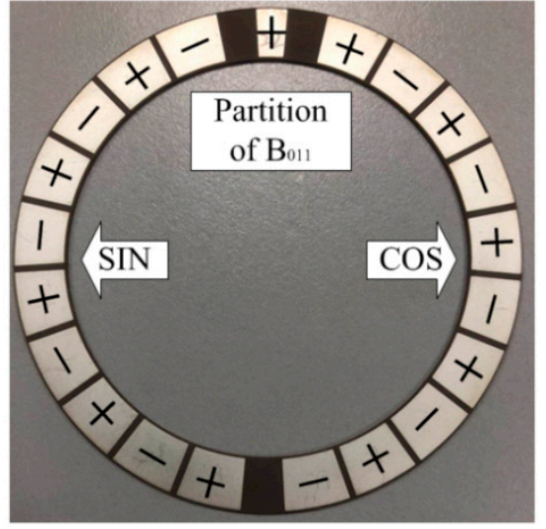

(b)

Figure 5. Different polarization partitions of PZT piezoelectric ceramics corresponding to different modes: (a) $\mathrm{B}_{09}$ and (b) $\mathrm{B}_{011}$.

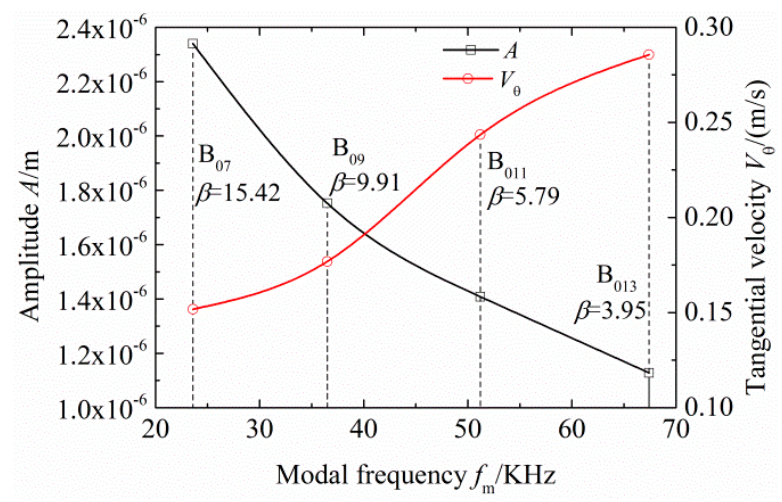

Figure 6. Stator vibration parameters affected by operating modal order.

\subsubsection{Influence of the Stator Structure Size on the Motor}

We adopted the $\mathrm{B}_{09}$ mode in the finite element geometrical model of the 70HA stator. When the tooth spacing was changed, the modal frequency, amplitude, and tangential velocity of the stator changed little. As the tooth spacing was decreased, the amplitude-velocity ratio of the stator increased slightly, as shown in Figure 7. In addition, the smaller the spacing, the larger the actual contact area between the stator and the rotor, which helps improve the rotational stability and output torque of the motor.

With the tooth spacing determined, the simulated effects of tooth height and base thickness on the stator vibration parameters could be ascertained and are shown in Figure 8. The thicker the stator base, the higher the modal frequency with a relationship that is approximately linear. When the base thickness was kept constant, the modal frequency and the amplitude decreased and the tangential velocity increased as the tooth height increased. In addition, as the base thickness was increased, the amplitude decreased sharply initially and then gently, and the tangential velocity increased initially and then decreased, which shows that the rotational speed is the result of multivariable coupling of the stator. The tooth height has an obvious influence on the tangential velocity. When the base thickness is small, the amplitude difference is also obvious whether there are stator teeth or not. When the base thickness and tooth height are smaller, the amplitude-velocity ratio is larger. 


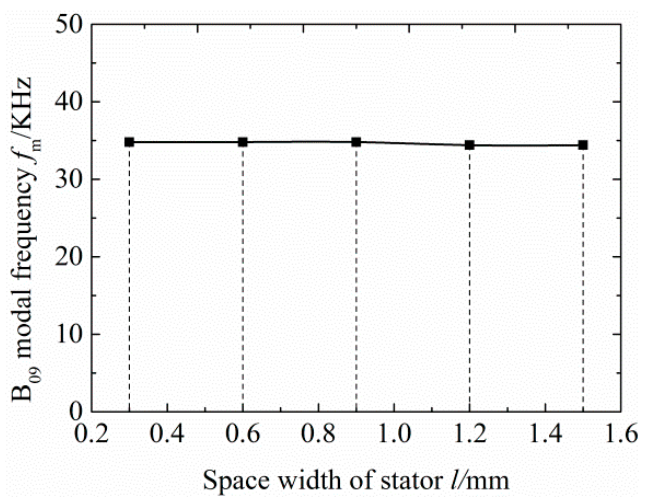

(a)

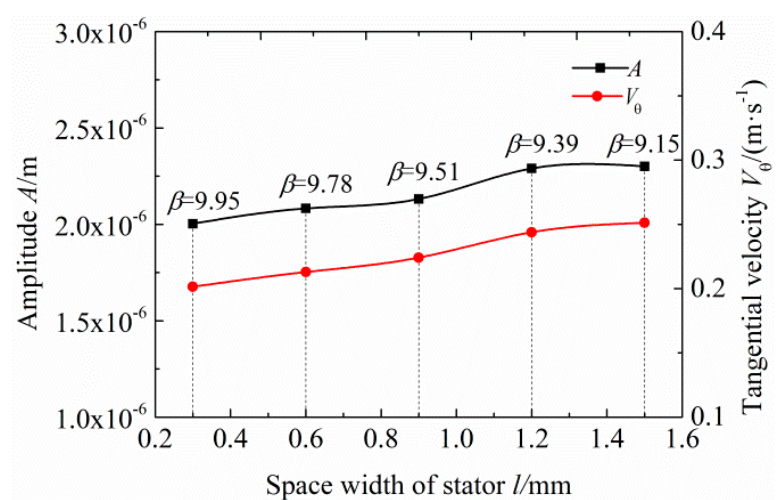

(b)

Figure 7. (a) Modal frequency affected by the space width of the stator and (b) amplitude affected by the space width of the stator.

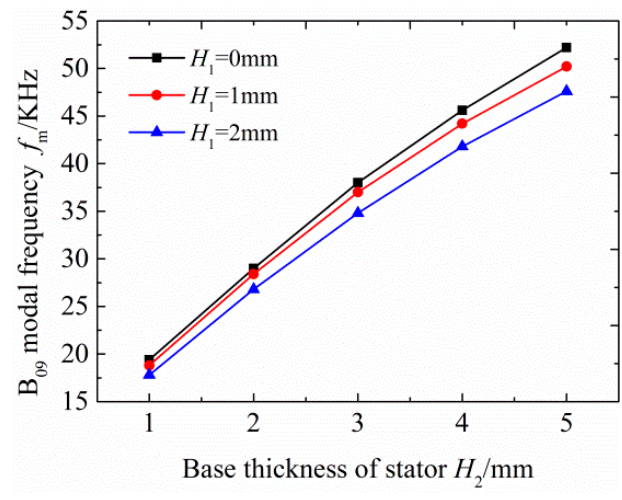

(a)

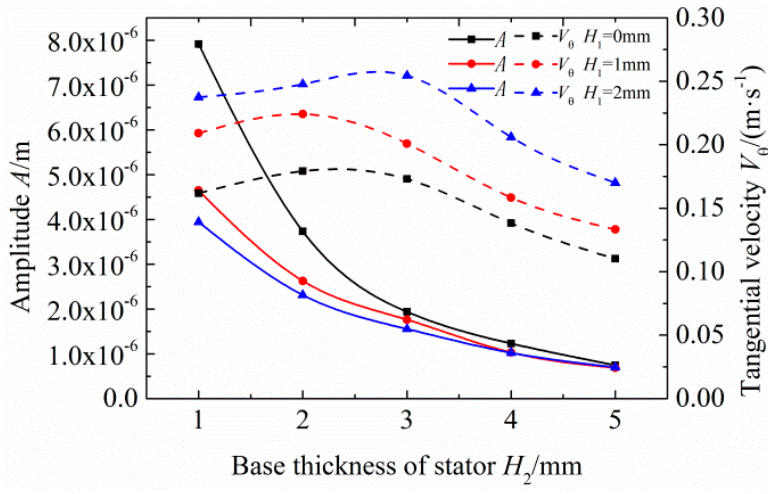

(b)

Figure 8. (a) Modal frequency affected by the base thickness and tooth height of the stator and (b) amplitude affected by the base thickness and tooth height of the stator.

\subsection{Determination of Improved Stator Characteristic Parameters}

In summary, the conditions of the low-speed-high-torque characteristics of TRUM-70HB can be further parameterized: when the outer diameter and the external drives are certain, ensure that the working modal frequency of the motor is slightly higher than $20 \mathrm{kHz}$. By analyzing the influence of each parameter on the stator vibration characteristics, the stator base thickness and the tooth height should be reduced first, and then the stator working mode order and tooth spacing should be reduced. Considering the factors of processing technology and cost, the variable design space can be reduced further. Thus, the enumeration method was used to select several sets of suitable parameters for simulation comparison, and finally, a set of parameters was determined. The improved motor was named $70 \mathrm{HB}$, and its stator characteristic parameters are compared in Table 2 with those of the conventional 70HA.

Table 2. Comparison of the stator characteristic parameters of 70HA and 70HB.

\begin{tabular}{cccc}
\hline Stator Parameters & 70HA & 70HB & Design Space \\
\hline Outer radius $r_{c}(\mathrm{~mm})$ & 35 & 35 & $\{35\}$ \\
Inner radius $r_{d}(\mathrm{~mm})$ & 24 & 24 & $\{24\}$ \\
Base thickness $H_{2}(\mathrm{~mm})$ & 2.5 & 1.5 & {$[1,5]$} \\
Tooth height $H_{1}(\mathrm{~mm})$ & 1 & 0.8 & {$[0.5,2.5]$} \\
Tooth spacing $l(\mathrm{~mm})$ & 0.8 & 0.3 & {$[0.3,1.5]$} \\
Working mode order $n$ & 11 & 9 & $\{7,9,11\}$ \\
\hline
\end{tabular}


The simulation gave a 70HB vibration modal frequency of $23.6 \mathrm{kHz}$, an amplitude of $3.68 \mu \mathrm{m}$, a tangential velocity of $0.1999 \mathrm{~m} / \mathrm{s}$, and an amplitude-velocity ratio of 18.41, as shown in Figure 9 . Furthermore, using ANSYS for phase response analysis, the motion trajectory of the outer edge of the stator teeth surface in one vibration period could be obtained. When the rotor was not considered, the normal and tangential amplitudes of $70 \mathrm{HA}$ were $1.41 \mu \mathrm{m}$ and $0.743 \mu \mathrm{m}$, respectively, and the normal and tangential amplitudes of $70 \mathrm{HB}$ were $3.68 \mu \mathrm{m}$ and $0.716 \mu \mathrm{m}$, respectively, as shown in Figure 10a. When considering the rotor preload $(550 \mathrm{~N})$, the normal and tangential amplitudes of 70HA were $0.341 \mu \mathrm{m}$ and $0.397 \mu \mathrm{m}$, respectively, and the normal and tangential amplitudes of $70 \mathrm{HB}$ were $0.965 \mu \mathrm{m}$ and $0.316 \mu \mathrm{m}$, respectively, as shown in Figure 10b. The simulation results show that the normal and tangential amplitudes of the stator will decrease when the preload exists, and the normal amplitudes will decrease greatly. The elliptical motion trajectory of the stator changes greatly when the stator characteristic parameters are changed: that of 70HA appears short and fat whereas that of the improved 70HB appears tall and thin. Due to the existence of the stator teeth, the deformation of the tooth structure at different positions may have a phase difference which is nonzero at the outer edge of the teeth. Therefore, the elliptical trajectory appears to be inclined.

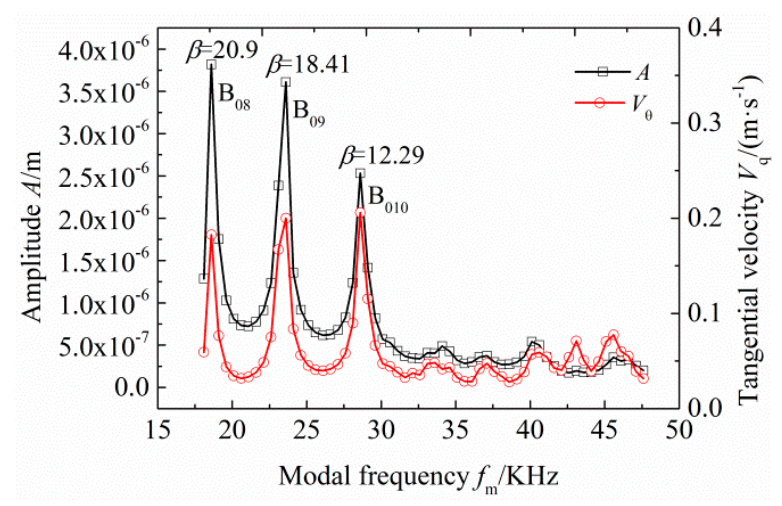

Figure 9. Simulation curves of the stator vibration parameters of $70 \mathrm{HB}$.

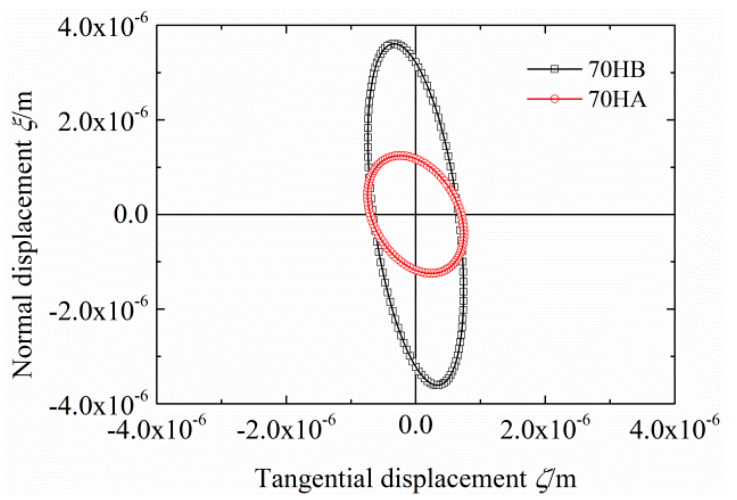

(a)

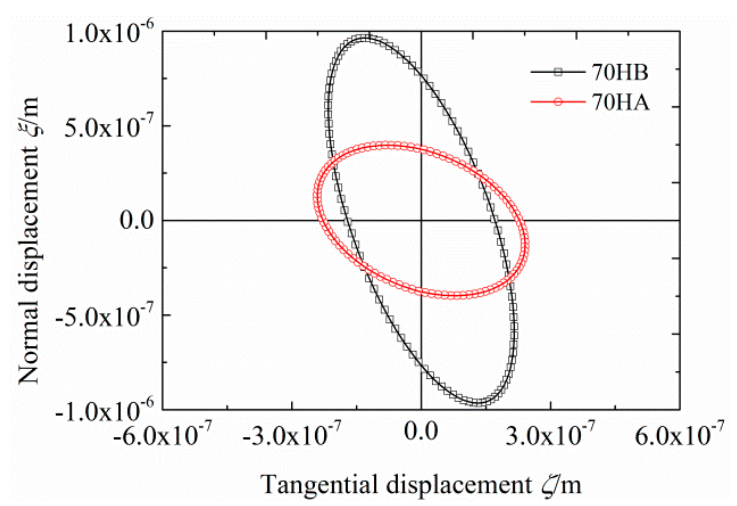

(b)

Figure 10. Comparison of stator elliptical motion traces between 70HA and 70HB: (a) response without the rotor $($ preload $=0 \mathrm{~N})$ and $(\mathbf{b})$ response with the rotor $($ preload $=550 \mathrm{~N})$.

\section{Experiments on Prototype Motors}

Following the simulation analysis, two sets of prototype motors were fabricated and named 70HA-1, 70HA-2, 70HB-1, and 70HB-2, respectively, as shown in Figure 11. Then, the vibration characteristics and the mechanical characteristics were tested. The experiment's final results showed that the consistency of 70HA and 70HB was good. 


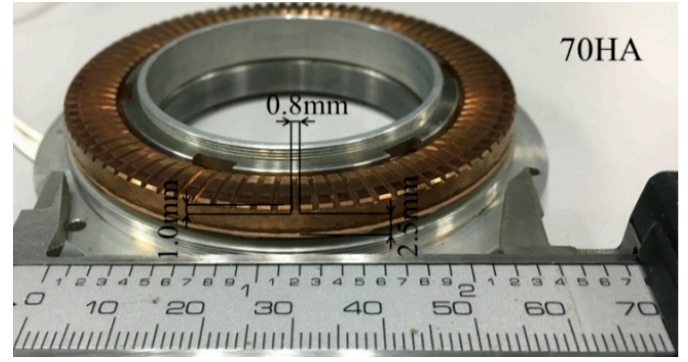

(a)

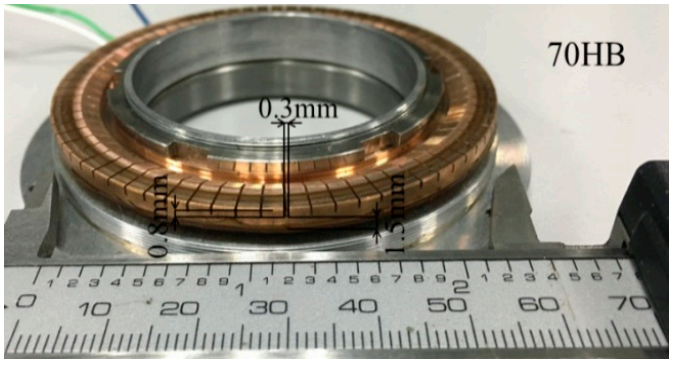

(b)

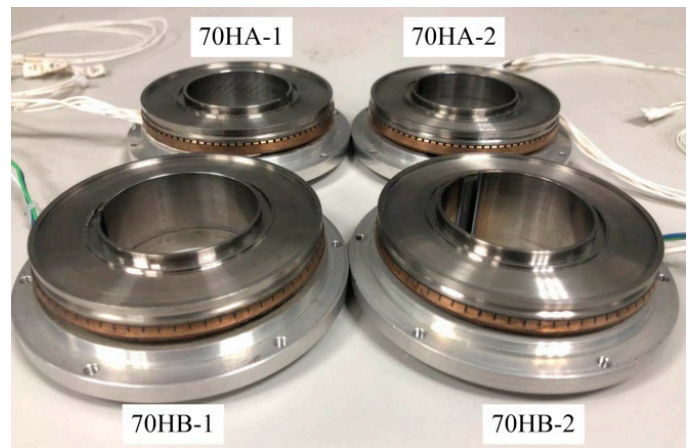

(c)

Figure 11. Comparison of stators and motors: (a) stator of 70HA; (b) stator of 70HB; and (c) two sets of prototype motors.

\subsection{Test of Vibration Characteristics}

In this study, vibration tests of the stators were conducted using a scanning Doppler laser vibration measurement system (PSV-300; Polytec Co., Karlsruhe, Germany). The instrument and the software interface are shown in Figure 12. The driving voltage was set to $100 \mathrm{~V}_{\mathrm{pp}}$. The actual modal frequency of 70HA-1 was $49.52 \mathrm{kHz}$ and the actual amplitude was $1.4 \mu \mathrm{m}$; the corresponding values for 70HA-2 were $49.58 \mathrm{kHz}$ and $1.4 \mu \mathrm{m}$, respectively; the corresponding values for $70 \mathrm{HB}-1$ were $22.07 \mathrm{kHz}$ and $3.5 \mu \mathrm{m}$, respectively; and the corresponding values for $70 \mathrm{HB}-2$ were $22.12 \mathrm{kHz}$ and $3.6 \mu \mathrm{m}$, respectively. In addition, some of the electrical properties of the stator were also tested using an impedance analyzer (Agilent 4294A; Agilent Technologies Inc., Shanghai, China). The measured results agree well with those from the simulation, as shown in Table 3, thereby verifying the accuracy of the simulation design. The test also showed that the individual differences in the prototypes are very small. Therefore, in the subsequent mechanical characteristics test, comprehensive performance data can be used to reflect the characteristics of the two types of motors.

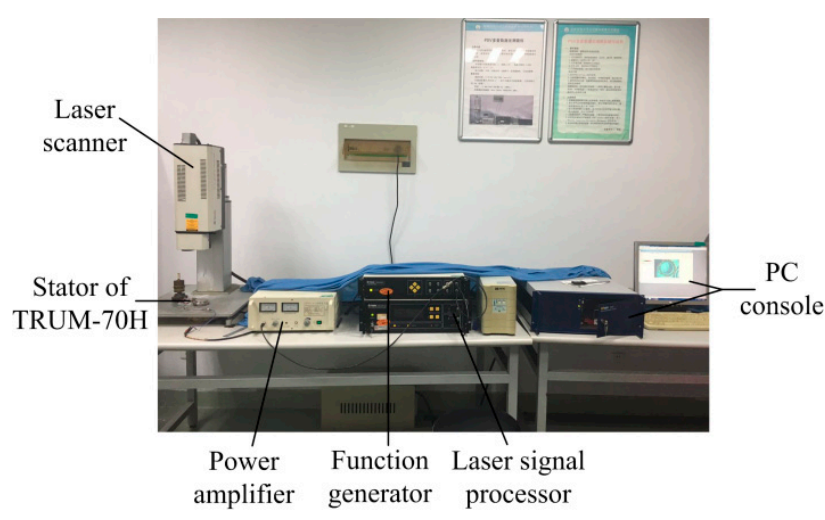

(a)

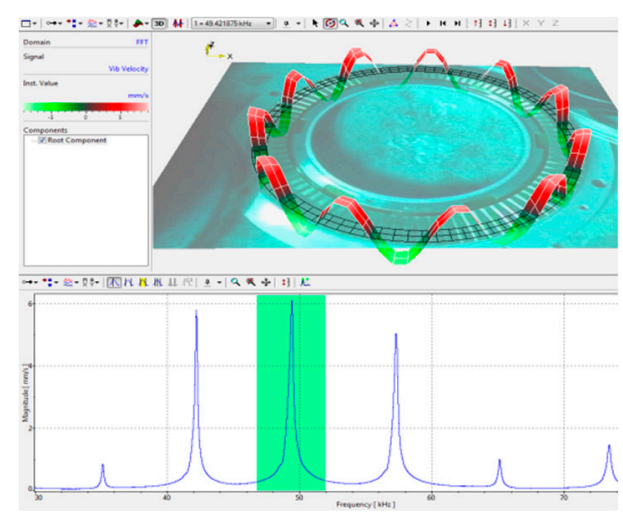

(b)

Figure 12. Cont. 


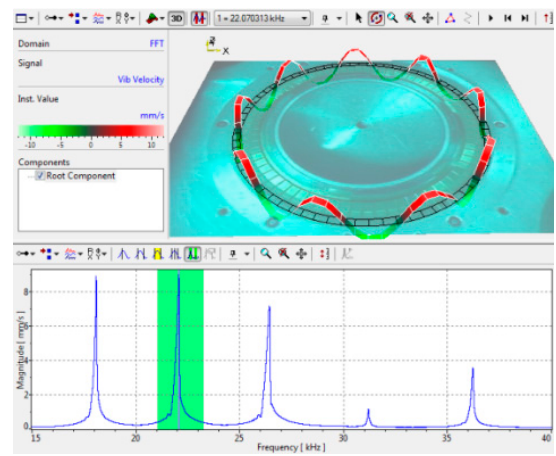

(c)

Figure 12. (a) PSV-300 scanning Doppler laser vibration measurement system; (b) measured mode of $70 \mathrm{HA}$; and (c) measured mode of $70 \mathrm{HB}$.

Table 3. Vibration characteristics measurement of 70HA and 70HB.

\begin{tabular}{|c|c|c|c|c|}
\hline Motor Type & 70HA-1 & 70НА-2 & 70HB-1 & 70HB-2 \\
\hline $\begin{array}{c}\text { Modal frequency } f_{m}(\mathrm{kHz}), \\
\text { simulation/measurement }\end{array}$ & $51.2 / 49.52$ & $51.2 / 49.58$ & 23.6/22.07 & 23.6/22.12 \\
\hline $\begin{array}{c}\text { Amplitude } w_{0}(\mu \mathrm{m}) \\
\text { simulation/measurement }\end{array}$ & $1.41 / 1.4$ & $1.41 / 1.4$ & $3.68 / 3.5$ & $3.68 / 3.6$ \\
\hline Error of $f_{m}$ & $3.39 \%$ & $3.16 \%$ & $6.93 \%$ & $6.27 \%$ \\
\hline Error of $w_{0}$ & $0.71 \%$ & $0.71 \%$ & $5.14 \%$ & $2.17 \%$ \\
\hline Static capacitance of PZT $C_{0}(\mathrm{nF})$ & 12.51 & 12.42 & 12.18 & 12.21 \\
\hline Resonant frequency of stator $f_{r}(\mathrm{kHz})$ & 51.09 & 50.86 & 21.58 & 21.72 \\
\hline Anti-resonant frequency of stator $f_{a}(\mathrm{kHz})$ & 51.80 & 51.52 & 22.39 & 22.49 \\
\hline
\end{tabular}

In order to test the amplitude of the stator with preload, a rotor with an outer diameter $4 \mathrm{~mm}$ smaller than that of the stator was made. Thus, the vibration of the stator teeth surface could be measured by laser scanning. When the excitation voltage was $100 \mathrm{~V}_{\mathrm{pp}}$, the normal amplitudes of $70 \mathrm{HA}$ and $70 \mathrm{HB}$ without preload were $1.4 \mu \mathrm{m}$ and $3.5 \mu \mathrm{m}$, respectively; their amplitudes with a preload of $800 \mathrm{~N}$ were $0.2 \mu \mathrm{m}$ and $0.5 \mu \mathrm{m}$, respectively. When the excitation voltage is $400 \mathrm{~V}_{\mathrm{pp}}$, the stator deformation will be larger without the compressed rotor, which will lead to ceramic breakage. Therefore, the minimum preload was set to $200 \mathrm{~N}$. At this level, the normal amplitudes of $70 \mathrm{HA}$ and $70 \mathrm{HB}$ were $3.5 \mu \mathrm{m}$ and $8.0 \mu \mathrm{m}$, respectively. An accompanying noise indicated that the preload was still too small. The amplitudes with a preload of $800 \mathrm{~N}$ were $0.6 \mu \mathrm{m}$ and $2 \mu \mathrm{m}$, respectively. As shown in Figure 13, the test results show that the normal amplitude of the stator teeth surface decreases with increasing preload and increases with increasing excitation voltage. The stator amplitude during operation of the motor was maintained above $1 \mu \mathrm{m}$, and the larger the stator amplitude without the rotor, the greater the preload that can be applied.

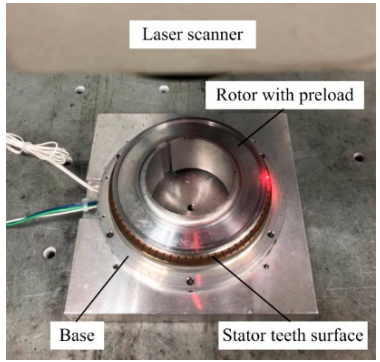

(a)

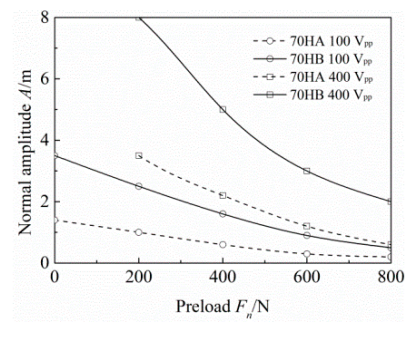

(b)

Figure 13. Normal amplitude test of the stator teeth surface with preload: (a) photograph of the experiment and (b) effect of preload and excitation voltage on the normal amplitude. 


\subsection{Test of Mechanical Characteristics}

A system was built to test the mechanical characteristics of the motors, as shown in Figure 14. The motor driver was composed of a TMS320F28335 DSP main processor with peripheral circuits, including a power module, signal processing module, two-phase power amplifier module, impedance matching module, and feedback signal acquisition module. The driver controlled the motor speed by frequency modulation, and the driving frequency was $22 \sim 30 \mathrm{kHz}$. The input voltage was $24 \mathrm{~V}$ DC and the output voltage was $350 \sim 450 \mathrm{~V}_{\mathrm{pp}}$ AC. The motor could realize millisecond start-stop and forward-reverse motion. The load device provided a load change of $0-3 \mathrm{~N} \cdot \mathrm{m}$ in $3 \mathrm{~s}$. The mechanical characteristics of 70HA and 70HB were measured and compared with those of the USM-60 motor (Shinsei Industrial Co., Ltd., Tokyo, Japan), which is the most representative traveling wave motor currently available; this is shown in Figure 15, where $\beta^{\prime}$ is the measured amplitude-velocity ratio. From Figure $15 \mathrm{a}$, the $\beta^{\prime}$ value of USM- 60 is 4.17 , which is the minimum; that of $70 \mathrm{HA}$ is 5.88 , and that of $70 \mathrm{HB}$ is 18.37 , which is the maximum. This means that the mechanical characteristics were changed from soft to hard. Compared with 70HA, the maximum speed of $70 \mathrm{HB}$ was reduced from $65 \mathrm{rpm}$ to $50 \mathrm{rpm}$ and the maximum stall torque was increased from $1.2 \mathrm{~N} \cdot \mathrm{m}$ to $2.4 \mathrm{~N} \cdot \mathrm{m}$. The operating frequency of $70 \mathrm{HA}$ is in the range $50.5-53.5 \mathrm{kHz}$, and the maximum efficiency is only roughly $10 \%$ at $50 \%$ of the maximum stall torque. The operating frequency of $70 \mathrm{HB}$ is in the range $25-28 \mathrm{kHz}$, and the maximum efficiency is roughly $27 \%$ at $55 \%$ of the maximum stall torque. Overall, the maximum speed of the improved $70 \mathrm{HB}$ dropped by $23.1 \%$, the maximum stall torque increased by $100 \%$, and the maximum efficiency increased by $170 \%$. In addition, we compared the $70 \mathrm{HB}$ with the same size motor in Ref. [11]. It can be seen that as the driving frequency decreases, the output speed and torque of both motors increase and peak near the resonance point. The output performance indicators drop sharply when the driving frequency is below the resonance point. Although the efficiency of $70 \mathrm{HB}$ is lower than that of the reference motor, the power consumption of $70 \mathrm{HB}$ is also relatively lower. The maximum input power of the reference motor is $70 \mathrm{~W}$, while that of $70 \mathrm{HB}$ is only $26 \mathrm{~W}$, as shown in Figure 15b,c. In summary, it is fully demonstrated that the design of 70HB's low-speed-high-torque characteristics was successful.

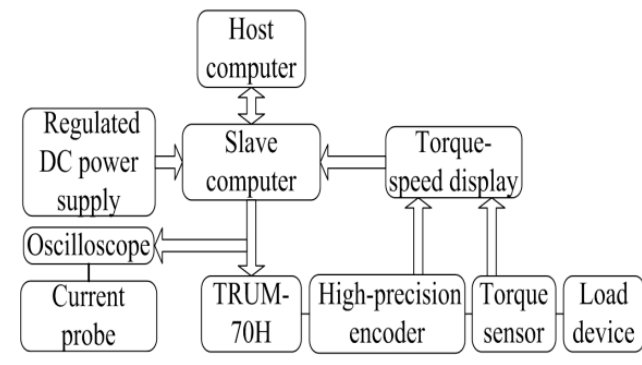

(a)

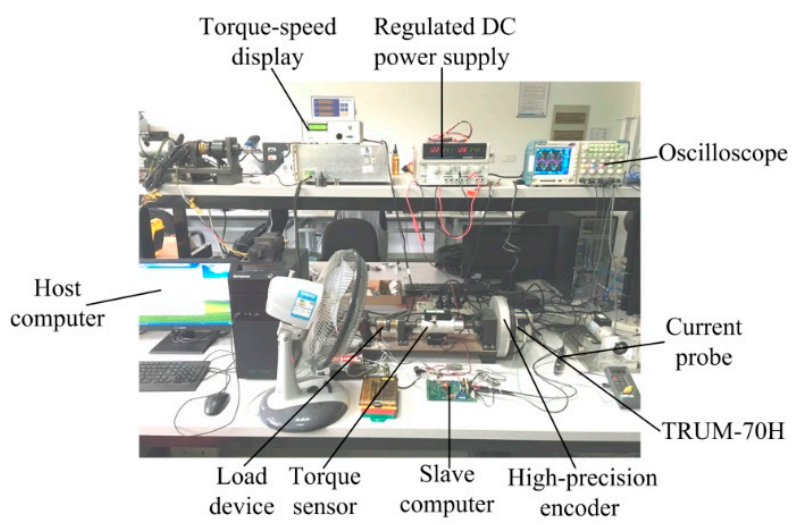

(b)

Figure 14. System for testing the mechanical characteristics of TRUMs: (a) a principle block diagram of the test system and (b) a photograph of the test system.

The measured vibration parameters were substituted into Equations (4) and (8) of Section 2. The preload was set to $550 \mathrm{~N}$ and the average dynamic friction coefficient was set to 0.2 . Thus, the limiting speed and the limiting stall torque of the motor could be calculated and were found to be slightly larger than the measured values, as shown in Tables 4 and 5. In summary, the simulation and calculation results play an important role in designing and improving the motor. 


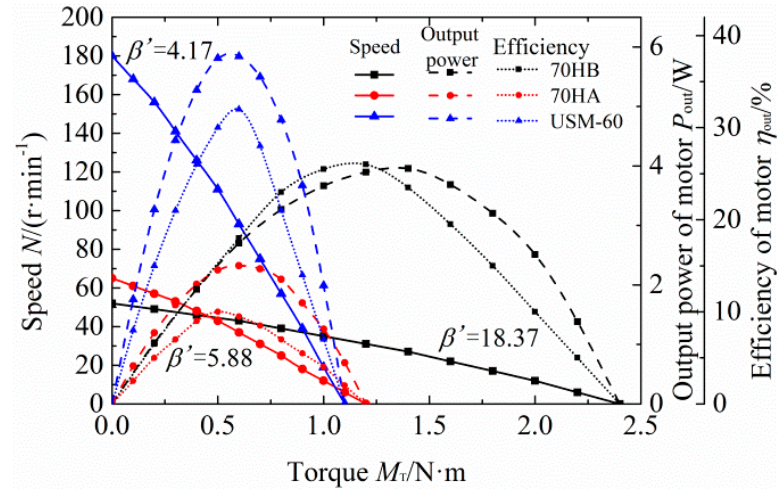

(a)

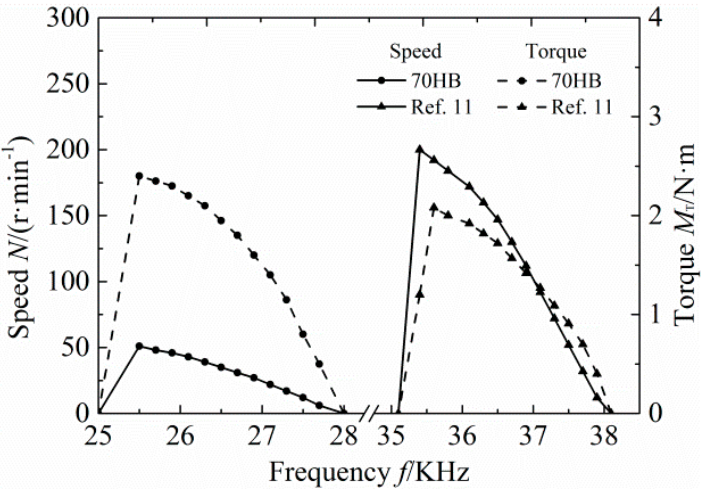

(b)

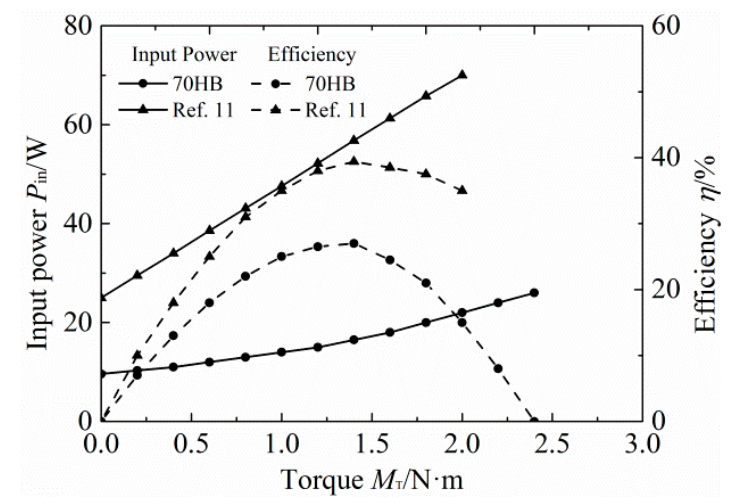

(c)

Figure 15. Performance curves of different motors: (a) mechanical characteristics of 70HA, 70HB, and USM-60; (b) mechanical characteristics of 70HB and the motor in Ref. [11]; and (c) power consumption of $70 \mathrm{HB}$ and the motor in Ref. [11].

Table 4. Results of maximum speed by simulation, calculation, and measurement.

\begin{tabular}{cccc}
\hline Motor Type & $\begin{array}{c}\text { Simulated Speed } \\
\boldsymbol{N}_{\max }(\mathbf{r p m})\end{array}$ & $\begin{array}{c}\text { Calculated Speed } \\
\boldsymbol{N}_{\mathbf{0}}(\mathbf{r p m})\end{array}$ & $\begin{array}{c}\text { Measured } \\
\boldsymbol{N}^{\prime}(\mathbf{r p m})\end{array}$ \\
\hline $70 \mathrm{HA}$ & 66.48 & 81.92 & 65 \\
$70 \mathrm{HB}$ & 54.57 & 52.73 & 50 \\
\hline
\end{tabular}

Table 5. Results of maximum stall torque by calculation and measurement.

\begin{tabular}{|c|c|c|}
\hline Motor Type & $\begin{array}{l}\text { Calculated Stall Torque } \\
\qquad M_{T 0}(\mathrm{~N} \cdot \mathrm{m})\end{array}$ & $\begin{array}{c}\text { Measured } \\
M_{T 0}^{\prime}(\mathrm{N} \cdot \mathrm{m})\end{array}$ \\
\hline $70 \mathrm{HA}$ & 1.70 & 1.2 \\
\hline $70 \mathrm{HB}$ & 2.82 & 2.4 \\
\hline
\end{tabular}

Because preload has a great influence on the output performance of the motor, it was necessary to analyze the influence of preload on the performance of the prototype. By adjusting the preload nut when assembling the motor, the mechanical output characteristics of the motor with different preload levels could be tested. The experiments showed that the no-load speed and stall torque of 70HA and $70 \mathrm{HB}$ were smaller when the preload was small (about $200 \mathrm{~N}$ ). With increasing preload, the no-load speed and stall torque of both motors increased rapidly and tended to be flat. The no-load speed and stall torque of 70HA reached their peak at about $600 \mathrm{~N}$, then decreased rapidly, and the motor failed to start at about $900 \mathrm{~N}$. The no-load speed and stall torque of $70 \mathrm{HB}$ reached their peak at about $700 \mathrm{~N}$, then decreased rapidly, and the motor failed to start at about $1000 \mathrm{~N}$. The optimum preload of both motors was larger than the preset $550 \mathrm{~N}$, and the optimum preload of $70 \mathrm{HB}$ was about $100 \mathrm{~N}$ larger 
than that of 70HA. The results also show that the 70HB stator has larger normal amplitude, which can make it withstand greater preload and significantly increases the stall torque, as shown in Figure 16.

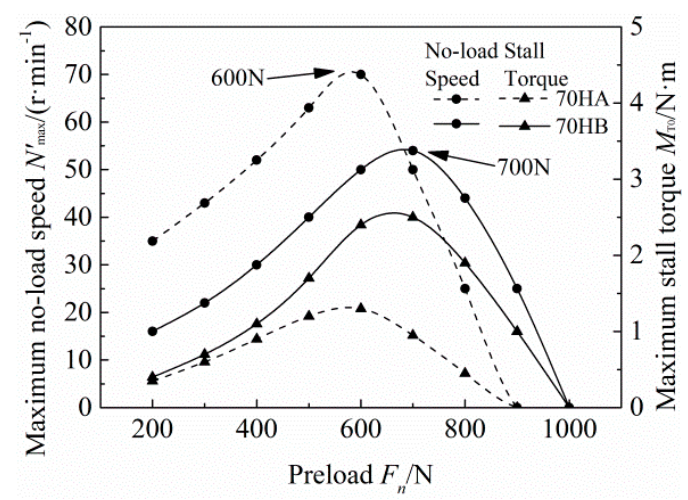

Figure 16. Effect of different preload levels on the mechanical output characteristics of 70HA and 70HB (driving frequency: $f_{70 \mathrm{HA}}=51.3 \mathrm{kHz}, f_{70 \mathrm{HB}}=25.4 \mathrm{kHz}$; excitation voltage: $U=440 \mathrm{~V}_{\mathrm{pp}}$ ).

In summary, the working principle and structure of the prototype may not be innovative, but we propose a new method from a technical point of view to make the motor have lower speed and greater torque, which is also emphasized in this paper. In order to further prove the validity of the research results, we compared the prototype with some commercial products and designs published in recent literature, such as the product PMR70ZK of NUAA Super Control Technology Co., Ltd. (www.scnuaa.com, China), the product USR60-S3 of SHINSEI Corporation (www.shinseimotor.com, Japan), the product PSM60S-A of Piezo Sonic Corporation (www.piezo-sonic.com, Japan), the polymer-based ultrasonic motor designed by Wu et al. [26], the metal/polymer-matrix material compound motor designed by Li et al. [27], and the ring-type motor using a radial bending mode designed by Chen et al. [28], all of which have similar structure and size, as shown in Table 6. From the list, it can be seen that the motor $70 \mathrm{HB}$ has the lowest maximum-speed but the highest stall-torque, showing significant low speed and large torque characteristics. It is proved that the prototype in this paper is unique.

Table 6. Performance comparison between $70 \mathrm{HB}$ and other motors.

\begin{tabular}{cccccccc}
\hline Performance Parameters & 70HB & PMR70ZK & USR60-S3 & PSM60S-A & Ref. [26] & Ref. [27] & Ref. [28] \\
\hline Outside diameter (mm) & 70 & 70 & 60 & 60 & 30 & 60 & 90 \\
Driving frequency (kHz) & $25 \sim 28$ & $37 \sim 43$ & $40 \sim 45$ & $40 \sim 45$ & $25 \sim 27$ & $40 \sim 45$ & $19 \sim 22$ \\
Driving voltage (Vrms) & $160 \pm 20$ & $160 \pm 20$ & 130 & 130 & 250 & 140 & 150 \\
Maximum speed (rpm) & 50 & 200 & 150 & 180 & 117.5 & 85 & 146 \\
Stall torque (N·m) & 2.4 & 1.6 & 1.0 & 1.2 & $9.5 \times 10^{-3}$ & 0.5 & 1.0 \\
Mass (g) & 210 & 350 & 258 & 230 & 2.5 & 224.5 & 180 \\
\hline
\end{tabular}

\section{Conclusions}

In this paper, the intrinsic influencing factors of the low-speed-high-torque characteristics of traveling wave motors were studied without changing the outer diameter or the external drives. It was noted that changing the size and shape of the elliptical motion of the stator is the fundamental way to realize low-speed-high-torque characteristics, whereupon the $70 \mathrm{H}$ hollow traveling wave motor was developed. A parameter $\beta$ for measuring the significance of the low speed and high torque of a traveling wave motor was proposed. The influence of the stator characteristic parameters on the amplitude-velocity ratio was simulated. The larger the value of $\beta$, the taller and thinner the elliptical motion trajectory of the stator and the more significant the low-speed-high-torque characteristics. Based on this, improved stator characteristic parameters were determined according to the simulation, and the two prototype motors $70 \mathrm{HA}$ and $70 \mathrm{HB}$ were fabricated. On testing the vibration and mechanical 
characteristics, the measured results were found to be consistent with the simulated ones. Compared with the conventional 70HA, the improved $70 \mathrm{HB}^{\prime}$ s maximum speed was reduced by $23.1 \%$ and its maximum stall torque was increased by $100 \%$. The motor speed changed less with load; that is, $70 \mathrm{HB}$ exhibited a harder mechanical characteristics curve. In addition, $70 \mathrm{HB}$ was lighter at $201 \mathrm{~g}$ and had a higher torque density of $11.43 \mathrm{~N} \cdot \mathrm{m} / \mathrm{kg}$, making it more suitable for aerospace applications. Finally, with a constant outer diameter of the motor, the methods for designing a low-speed-high-torque traveling wave motor stator are summarized as follows: (i) the motor should have a lower working mode order; (ii) the stator base thickness and tooth height should be reduced; (iii) the tooth spacing should be reduced and the contact range between the teeth and the rotor should be increased; and (iv) the actual operating frequency of the motor should be slightly higher than $20 \mathrm{kHz}$.

In the future, this prototype has the potential to be used as an actuator in the aerospace field, such as for satellite Control Moment Gyroscopes (CMGs). In order to control the attitude of a satellite, the motor usually requires very low speed but larger torque and higher positioning accuracy. The $70 \mathrm{HB}$ motor is simple in structure, small in size, and light in weight, and it does not need a deceleration mechanism, which effectively saves space and energy in a system.

Author Contributions: Conceptualization, J.L. and H.Z.; Methodology, J.L.; Software, J.L.; Validation, J.L., Z.-J.N.; Writing-original draft preparation, J.L.; Writing-review and editing, Z.-J.N. and H.Z.; Supervision, H.Z.; Project administration, C.-S.Z.

Funding: The research was funded by the National Basic Research Program of China (973 Program, grant number: 2015CB057501) and the Priority Academic Program Development of the Jiangsu Higher Education Institutions (PAPD).

Acknowledgments: The authors are very grateful to R. Xiao-Rong Lu and Rui-Hong Liang from the Shanghai Institute of Ceramics for providing various piezoelectric ceramics for the motors.

Conflicts of Interest: The authors declare no conflict of interest.

\section{References}

1. Nakamura, K.; Ueha, S. Performance of a hybrid transducer-type ultrasonic motor as a function of the size. In Proceedings of the 1994 IEEE Ultrasonic Symposium, Cannes, France, 31 October-3 November 1994; pp. 557-560.

2. Guo, J.; Gong, S.; Guo, H.; Liu, X.; Ji, K. Force transfer model and characteristics of hybrid transducer type ultrasonic motors. IEEE Trans. Ultrason. Ferroelectr. Freq. Control 2004, 51, 387-395. [PubMed]

3. Krome, J.W.; Wallaschek, J. Novel disk type ultrasonic traveling wave motor for high torque. In Proceedings of the IEEE Ultrasonics Symposium, Toronto, ON, Canada, 5-8 October 1997; pp. 385-390.

4. Satonobu, J.; Torii, N.; Nakamura, K.; Ueha, S. Construction of megatorque hybrid transducer type ultrasonic motor. Jpn. J. Appl. Phys. 1996, 35, 5038-5041. [CrossRef]

5. Sato, K.; Aoyagi, M.; Ogasawara, T.; Tomikawa, Y. Ultrasonic motor using a large-diameter torsional vibrator with slant slits. Jpn. J. Appl. Phys. 1995, 34, 2707-2710. [CrossRef]

6. Oh, J.H.; Yuk, H.S.; Lim, K.J. Design of a novel type ultrasonic motor for high torque generation. J. Electroceram. 2013, 30, 113-117. [CrossRef]

7. Oh, J.H.; Jung, H.E.; Lee, J.S.; Lim, K.J.; Kim, H.H.; Ryu, B.H. Design and performances of high torque ultrasonic motor for application of automobile. J. Electroceram. 2009, 22, 150-155. [CrossRef]

8. Dong, Z.; Yang, M.; Chen, Z.; Xu, L.; Meng, F.; Ou, W. Design and performance analysis of a rotary traveling wave ultrasonic motor with double vibrators. Ultrasonics 2016, 71, 134-141. [CrossRef] [PubMed]

9. An, D.; Yang, M.; Zhuang, X.; Yang, T.; Meng, F.; Dong, Z. Dual traveling wave rotary ultrasonic motor with single active vibrator. Appl. Phys. Lett. 2017, 110, 143507. [CrossRef]

10. Glenn, T.S.; Hagood, N.W. Development of a two-sided piezoelectric rotary ultrasonic motor for high torque. Smart Mater. Struct. 1997, 3041, 326-338.

11. Kawai, Y.; Asai, K.; Naito, S.; Fukui, T.; Adachi, Y.; Handa, N. High power travelling-wave type ultrasonic motor. Jpn. J. Appl. Phys. 1995, 34, 2711-2714. [CrossRef]

12. Li, H.; Gu, C. Research on large torque travelling wave ultrasonic motor. Proc. CSEE 2002, 22, 67-70. 
13. Tian, X.; Wang, Y.; Lang, Y.; Li, J. Development of a hollow ring-type of travelling wave ultrasonic motor. J. Vib. Meas. Diagn. 2013, 33, 190-193.

14. Mo, Y.; Hu, M. Study of large torque pressure-equalizing traveling wave type ultrasonic motor. Trans. Chin. Electrotech. Soc. 2002, 17, 7-11.

15. Chen, Y.; Liu, Q.; Zhou, T. A traveling wave ultrasonic motor of high torque. Ultrasonics 2006, 44, e581-e584. [CrossRef] [PubMed]

16. Tsujino, J.; Suzuki, R.; Takeuchi, M. Load characteristics of ultrasonic rotary motor using a longitudinal-torsional vibration converter with diagonal slits. Large torque ultrasonic rotary motor. Ultrasonics 1996, 34, 265-269. [CrossRef]

17. Ren, W.; Yang, L.; Ma, C.; Li, X.; Zhang, J. Output performance simulation and contact analysis of traveling wave rotary ultrasonic motor based on ADINA. Comput. Struct. 2019, 216, 15-25. [CrossRef]

18. Zhao, C. Ultrasonic Motors: Technologies and Applications; Springer: Berlin, Germany, 2011.

19. Zhu, M. Contact analysis and mathematical modeling of traveling wave ultrasonic motors. IEEE Trans. Ultrason. Ferroelectr. Freq. Control 2004, 51, 668-679. [PubMed]

20. Dong, Y. Traveling Ultrasonic Motors Based on Effective Elliptic Motion and Structural Force Factor; Hefei University of Technology: Hefei, China, 2015.

21. Mashimo, T.; Terashima, K. Experimental verification of elliptical motion model in traveling wave ultrasonic motors. IEEE ASME Trans. Mechatron. 2015, 20, 2699-2707. [CrossRef]

22. Renteria-Marquez, I.A.; Renteria-Marquez, A.; Tseng, B.T.L. A novel contact model of piezoelectric traveling wave rotary ultrasonic motors with the finite volume method. Ultrasonics 2018, 90, 5-17. [CrossRef]

23. Tao, Z.; Liu, B. Comparison of the traveling-wave ultrasonic motor with the ultrasonic motor using longitudinal and torsional vibration model. J. Zhengzhou Univ. Eng. Sci. 2009, 30, 60-64.

24. Duan, W.H.; Quek, S.T.; Lim, S.P. Finite element analysis of a ring type ultrasonic motor. In Proceedings of the Smart Structures and Materials 2005: Modeling, Signal Processing, and Control. International Society for Optics and Photonics, San Diego, CA, USA, 7-10 March 2005; Volume 5757, pp. 575-586.

25. Niu, Z.; Yan, F.; Sun, Z.; Yin, X. Study on nonlinear phenomenon of traveling wave ultrasonic motor based on the mechanism of vibration and electrical properties. Proc. CSEE 2017, 37, 4819-4825.

26. Wu, J.; Mizuno, Y.; Nakamura, K. Polymer-based ultrasonic motors utilizing high-order vibration modes. IEEE ASME Trans. Mech. 2018, 23, 788-799. [CrossRef]

27. Li, J.; Liu, S.; Zhou, N.; Yu, A.; Cui, Y.; Chen, P. A travelling wave ultrasonic motor with metal/polymer-matrix material compound stator. Smart Mater. Struct. 2018, 27, 015027. [CrossRef]

28. Chen, W.; Liu, Y.; Yang, X.; Liu, J. Ring-type traveling wave ultrasonic motor using a radial bending mode. IEEE Trans. Ultrason. Ferroelectr. Freq. Control 2014, 61, 197-202. [CrossRef] [PubMed] 